\title{
Temporomandibular Joint Arthroscopy
}

\author{
Edvitar Leibur ${ }^{1,2}$, Oksana Jagur $^{1}$ and Ülle Voog-Oras ${ }^{1}$ \\ ${ }^{1}$ Department of Stomatology, \\ 2Department of Internal Medicine, \\ Tartu University, University Hospital \\ Estonia
}

\section{Introduction}

Arthroscopy is a technique for direct visual inspection of internal joint structures, including biopsy and other surgical procedures performed under visual control. In 1918 Takagi first described arthroscopy of the knee joint examinations using cystoscope (Tag, 1939). Onishi in 1970 was the first to report arthroscopy of the human temporomandibular joint (TMJ) and the first results were published by him (Onishi, 1975, 1980). The progress in research and applications of TMJ arthroscopy in joint disease have led to the acceptance of small operative procedures as a safe, minimally invasive means of effectively treating a number of intra-articular and degenerative TMJ problems (McCain, 1992; Holmlund \&Axelsson, 1996; Holmlund et al., 2001). Arthroscopic surgery has been an effective treatment for TMJ disorders refractory to nonsurgical treatments ( Ohnuki et al., 2003; Gonzalez-Garcia et al., 2008, Leibur et al., 2010). TMJ arthroscopy has been variously reported as successful in up to $80 \%$ of cases where outcome of arthroscopic surgery to the TMJ correlates with the stage of internal derangement (K. Murakami et al., 2000; Sanroman, 2004). Studies have been variable in their scientific method and some long-term outcomes studies have been completed where both quality of life and functional outcome have been assessed (Voog et al., 2003a; Undt et al., 2006; Jagur et al., 2011). For enabling direct comparison of the clinical results following arthroscopic surgery and open surgery a retrospective study comparing two centers' results using the Jaw Pain and Function Questionnaire ( Clark et al., 1989) has been performed and these treatment results of open surgery were comparable with arthroscopic treatment results (Undt et al., 2006).

\section{Anatomy of the temporomandibular joint}

The temporomandibular joint is the articulation between the mandible and the cranium. The mandibular head (condyle), glenoid (mandibular) fossa, and articular eminence form the TMJ. These joints serve as one anatomic control for both mandibular movement and the occlusion, surrounded by a capsule which consists of fibrous material, and a synovial lining. The capsule is quite thin anteromedially and medially $\sim 0,7 \mathrm{~mm}$ and thick laterally and posteriorly $\sim 1,8 \mathrm{~mm}$. The inner layer of the capsule or synovial membrane is highly vascularized layer of endothelial origin cells, producing synovial fluid. The capsule stretches from the edge of the mandibular fossa to the neck of the mandible, proximal to the pterygoid fovea, and envelops the articular eminence. TMJ is reinforced by the temporomandibular and sphenomandibular ligaments. The articular surface of the 
mandible is the upper and anterior surface of the condyle, lined by dense, avascular fibrous connective tissue. A layer of hyaline cartilage covers the articulating cortical bone. The adult human condyle is about 15 to $20 \mathrm{~mm}$ from side to side and 8 to $10 \mathrm{~mm}$ from front to back. The articular surface is convex when viewed from the side and less when viewed from the front. Glenoid fossa is the concavity within the temporal bone. The anterior wall is formed by the articular eminence of the temporal bone and its posterior wall by the tympanic plate, which also forms the anterior wall of the external auditory meatus. An articular disc is interposed between the temporal bone and the mandible, dividing the articular space into upper and lower compartments. The interposed fibrocartilaginous disc has a bow-tieshaped biconcave morphology. The anterior and posterior ridges of the disc are termed anterior and posterior bands and are longer in the mediolateral than in the anteroposterior dimension. The smaller anterior band attaches to the articular eminence, condylar head, and joint capsule. The posterior band blends with highly vascularized, loose connective tissue, the bilaminar zone, and the capsule, the bilaminar zone residing in the retrodiscal space in the mandibular fossa and attaching to the condyle and temporal bone. Medially and laterally, the disc is firmly attached to the capsule and the condylar neck. Anteromedially, it is attached to the superior part of the pterygoid muscle. In a physiologic joint, the disc is positioned between the mandibular head inferiorly and the articular eminence anteriorly and superiorly when the jaw is closed. The posterior band of the disc lies within $10^{\circ}$ of the 12 o'clock position. The medial and lateral corners of the disc align with the condylar borders and do not bulge laterally or medially. When the jaw is opened, the disc slides into a position between the mandibular head and articular eminence. The loose tissue of the bilaminar zone allows the remarkable range of motion of the disc. The attachments of the disc prevent luxation during opening. A triangular lateral ligament acts as a strong lateral stabilizer and inhibits the posterior translation of the mandibular head (Fig. 1).

The muscles of mastication are responsible for the complex movement of the jaw. The temporal, medial pterygoid, and masseter muscles facilitate jaw closure. Mouth opening is effected by coordinated action of the lateral digastric, mylohyoid, and suprahyoid muscles. The lateral pterygoid muscle and part of the fibers of the masseter and medial pterygoid muscles effect the anterior translation of the mandible. The superior belly of the lateral pterygoid muscle originates from the greater sphenoid wing and inserts on the disc. Subsequently, the superior belly plays a key role in upholding the physiologic position of the disc as it pulls the disc forward when the jaw is opened, in a combined translation and rotation. The inferior head of the lateral pterygoid muscle stretches from the lateral lamina of the pterygoid process to the pterygoid fovea. The medial pterygoid muslcle originates from the pterygoid fossa and inserts near the medial aspect of the mandibular angle (Sommer et al., 2003). The blood supply to the TMJ, outer and inner ear is provided mainly by branches from the internal maxillary artery as follows: temporal superficial artery, superior auricular artery, anterior tympanic artery and pterygoid artery. Innervation is provided by the auriculotemporal nerve (sensory branch of the mandibular nerve), deep temporal nerve, masseteric nerve. Sensory cervical sympathetic ramifications are going to the disc and capsule. The auriculotemporal nerve runs medial to the joint, then runs laterally, crossing the condylar neck, where it divides into branches to innervate the capsule, disc attachments, the tympanic membrane, the anterior surface of the cochlea, the upper part of the auricle, the tragus of the ear, the skin lining the external auditory meatus, the temporal region,. Nerve receptors as Ruffin receptors, Golgi tendon organs, Vater-Pacini corpuscules free nerve endings are in the capsule and substance $\mathrm{P}$ nerve fibres are also available in both the auriculotemporal and masseteric nerves, and have been demonstrated in the capsule, disc attachments but they are not present in the disc (Fig. 2). 


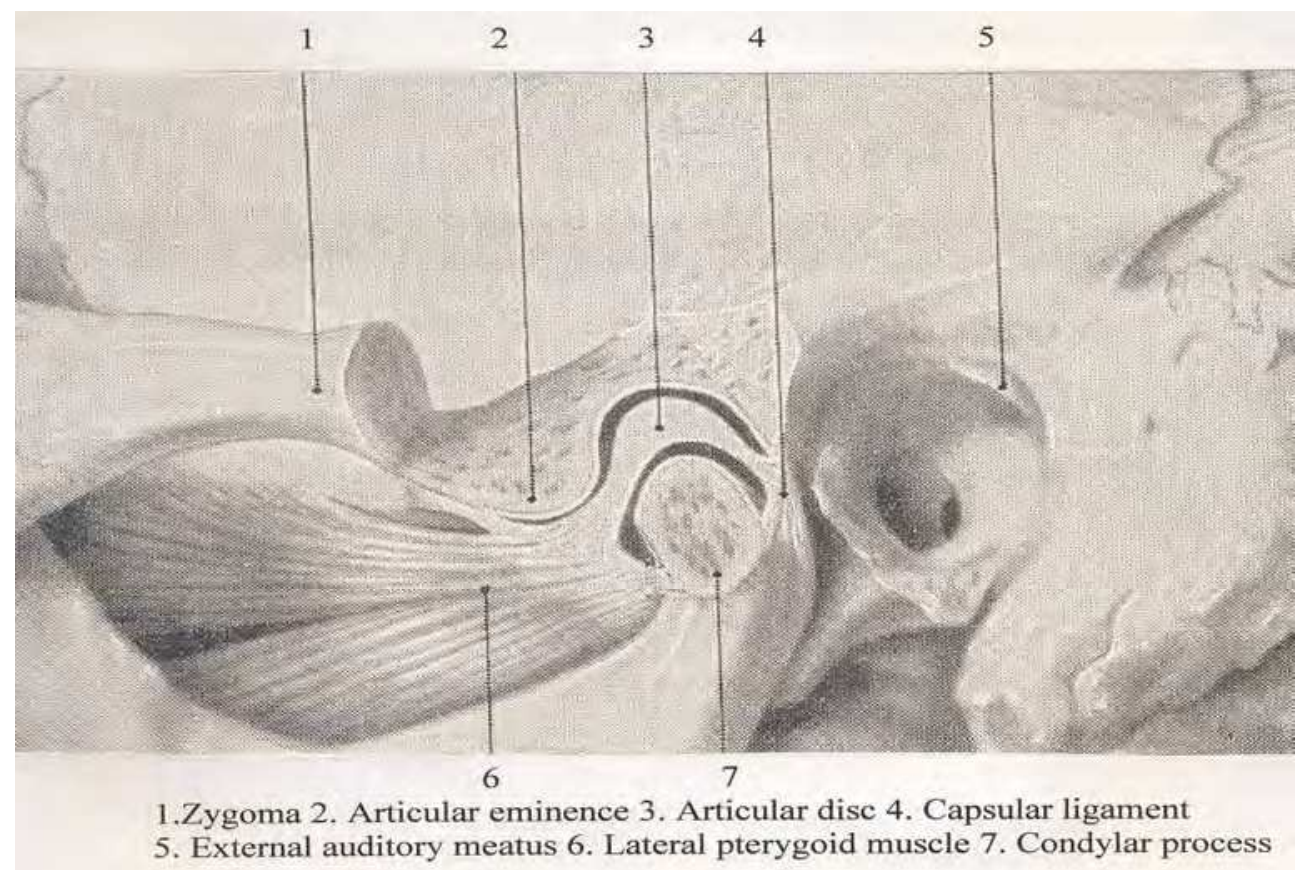

Fig. 1. A sagittal section through the left temporomandibular joint .

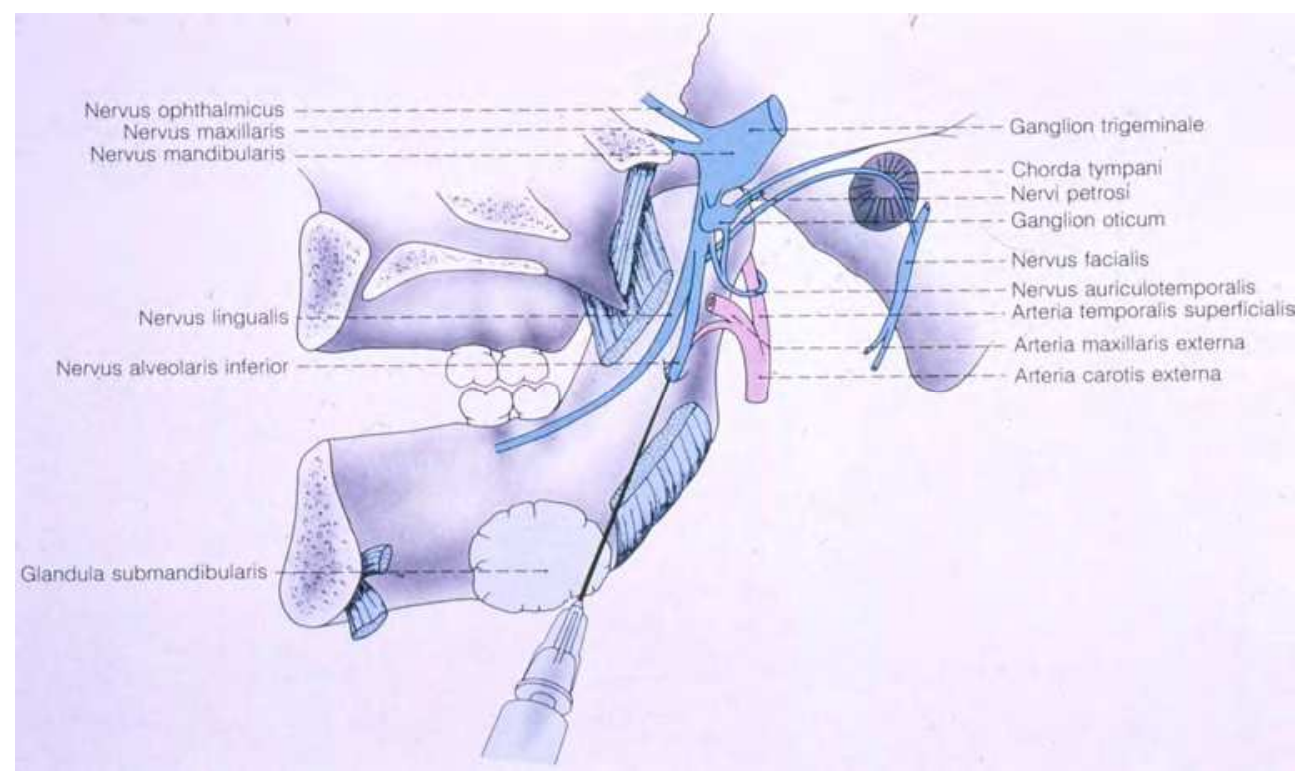

Fig. 2. Branches of trigeminal nerve. Innervation and blood supply of temporomandibular joint (by R.Schmelzle, 1989). 


\section{Classification of temporomandibular joint disorders:}

- $\quad$ Arthritis- acute, chronic, infectious (specific, nonspecific)

- Osteoarthritis/arthrosis - most often disorder

- Injuries - luxations, concussion, fracture

- Ankylosis (fibrous, fibro-osseous, osseous)

- Tumours (benign and malignant)

- Congenital disturbances: I \& II branchial arch malformations, condylar hypo-, hyperplasia

- Idiopathic condylar resorption

- $\quad$ Systemic conditions affecting the TMJ (rheumatoid arthritis, psoriasis, pseudogout etc.)

\section{Aetiology and pathogenesis of temporomandibular disorders}

\subsection{Aetiology}

Most scientists regard osteoarthritis as an inflammatory process, being most frequent TMJ disorder, characterised with proliferative changes in the synovia and primary degeneration of the cartilage and surrounding tissues with destruction of the bone structures. (Holmlund \& Axelsson, 1996; Emshoff , 2005). It is found that $28 \%$ of the adult population have signs of temporomandibular joint disorder. In systemic diseases (rheumatoid arthritis, psoriasis etc.) involvement of TMJ occurs (Voog et al., 2003b; 2004). Main aetiological factors of TMJ disorders are as follows: systemic diseases ( rheumatoid arthritis, psoriasis, pseudogout, ankylosing spondylitis etc.), secondary inflammatory component from the neighbouring regions (otitis, maxillary sinusitis, tonsillitis ), trauma (chronical), prevalence of dental arch defects e.g. missing of molar teeth, (Tallents et al. 2002), malocclusion, endocrinological disturbances, odontogenic infections (third molars). Presence of specific bacterial species as Staphylococcus aureus, Streptococcus mitis, Mycoplasma fermentas, Actinobacillus actinomycetemcomitans ( $\mathrm{Aa}$ ) in the synovial fluid have been found (Kim et al., 2003). Serum antibodies against Chlamydia spp. in patients with monoarthritis of the TMJ have been occurred. An association may exist between the presence of Chlamydia trachomatis and TMJ disease (Paegle et al., 2004).

\subsection{Pathogenesis}

Knowledge about the pathogenesis on a molecular level of disorders of the TMJ has been improved in recent years giving a possibility to use these data for the evidence based treatment. Inflammation mainly affects the posterior disc attachement (Holmlund \& Axelsson, 1996; Leibur et al., 2010). Several inflammatory mediators play an important role in the pathogenesis of TMJ diseases as tumor necrosis factor a (TNFa), interleukin-1 $\beta$ (IL-1 $\beta$ ), prostaglandin $\mathrm{E}_{2}\left(\mathrm{PGE}_{2}\right)$, leukotrien $\mathrm{B}_{4}\left(\mathrm{LkB}_{4}\right)$, matrix metalloproteinases $\left(\mathrm{MMP}_{\mathrm{s}}\right)$, serotonin- 5hydroxytryptamine (5-HT), (Alstergren et al., 1999; Voog et al., 2003b). MMP are responsible for the metabolism of extracellular matrix, being an early marker to determine TMJ arthritis. High level of MMP-3 has been determined in the synovial fluid in TMJ osteoarthritis patients (Kamada et al., 2000). Serotonin, mediator of pain and inflammation, is produced in the enterocromaffin cells of the gastrointestinal mucosa and absorbed by platelets. It is produced also in the synovial membrane and is present in the synovial fluid and in blood in case of rheumatoid arthritis and is involved in the mediation of TMJ pain in systemic inflammatory joint diseases (Alstergren \& Kopp, 1997; Voog et al., 2000). It plays a role also in bone metabolism (Warden \& Haney, 2008). Tissue response in case of inflammation is as follows: 
vasodilatation, extravasation, releasing of mediators, activation of nociceptors, release of neuropeptides as substance $\mathrm{P}(\mathrm{SP})$, neuropeptide $\mathrm{Y}(\mathrm{NPY})$, which stimulate releasing of histamin and serotonin from afferent nerve endings and hyperalgesia in TMJ occurs.

\section{Diagnostics of the temporomandibular disorders}

\subsection{Clinical data}

The most frequent complaint is pain and a decrease in the maximal interincisal opening (MIO), which normal values are between $35-50 \mathrm{~mm}$ (Fig. 3).

The following symptoms as pain (at rest, during maximum mouth opening and upon chewing), tenderness to digital palpation of the joint, sounds (clicking, crepitation), restricted mandibular mobility e.g. difficulty in opening the mouth, intermittent lock, closed lock, stiffness in the morning are observed. The stages of disease are usually classified according to Wilkes (1989; Table 1) by reviewing the case histories, clinical data, radiological records (computerized tomography images, magnetic resonance images, ortopantomography and/or plain radiographs by Schüller, Parma).

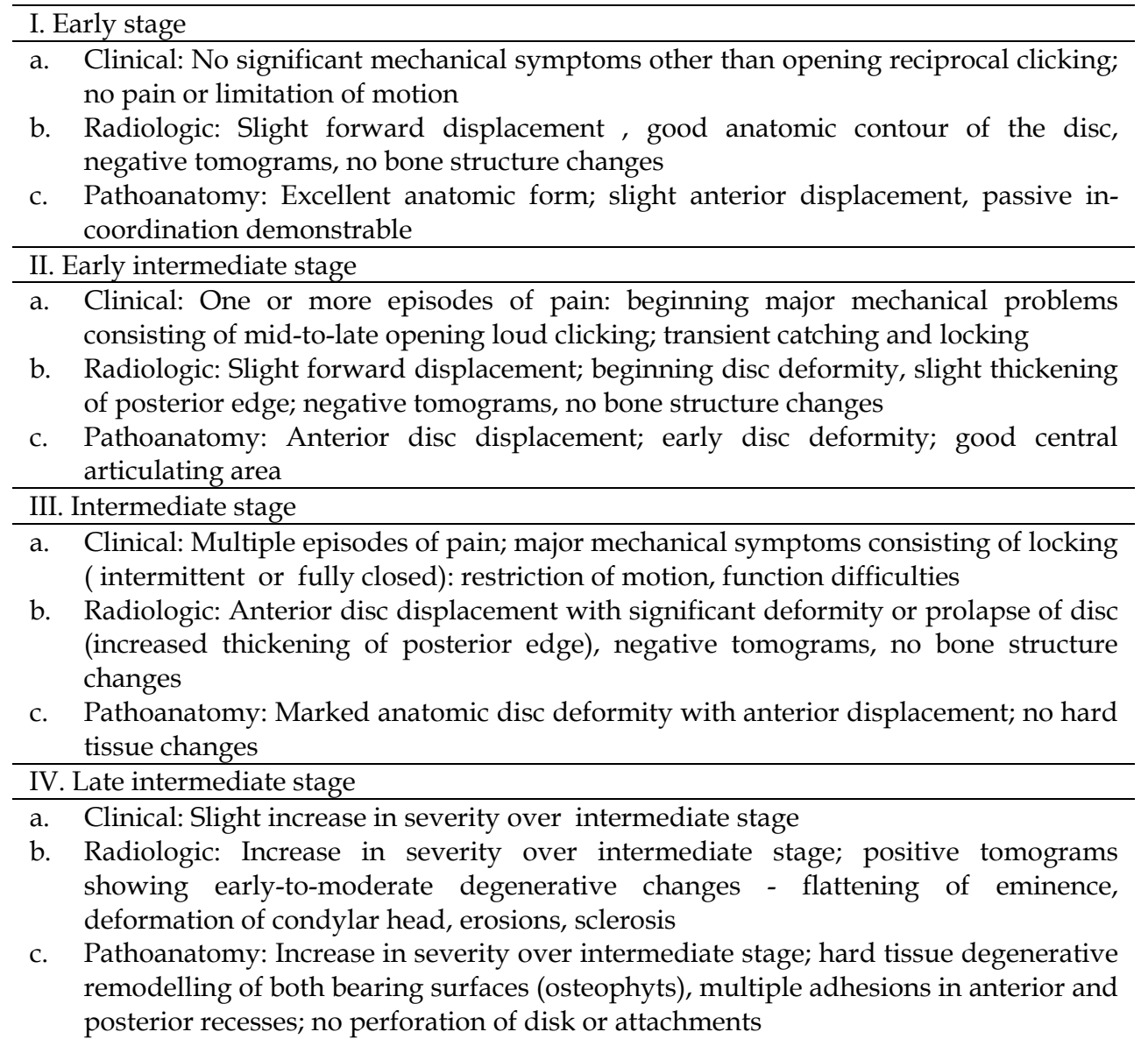




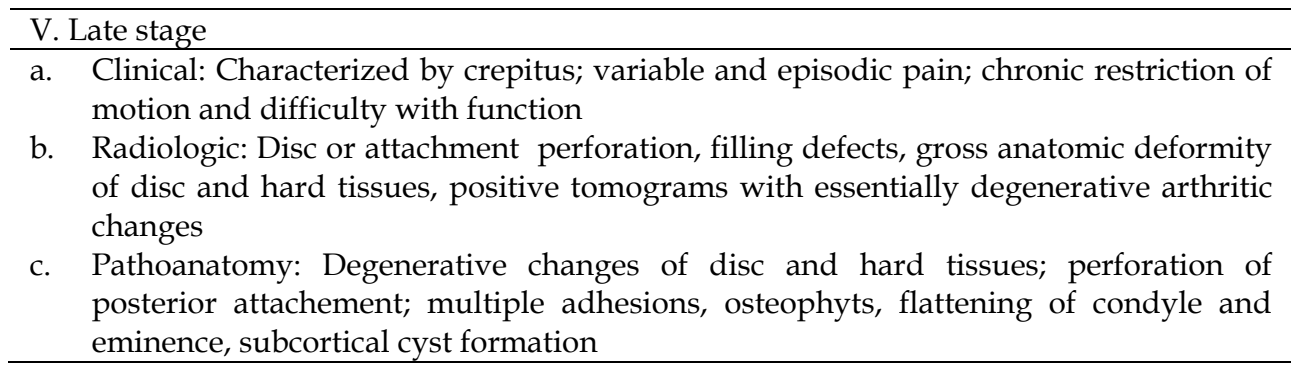

Table 1. Classification for internal derangement of the TMJ by Wilkes (1989).

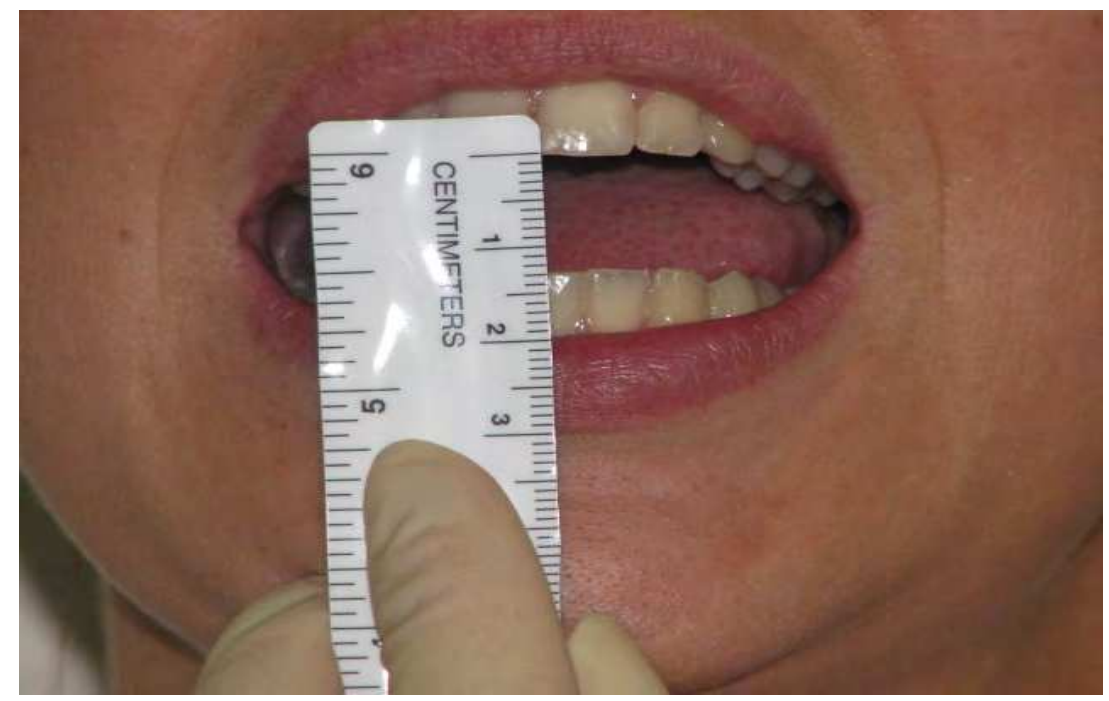

Fig. 3. Maximal interincisal opening (MIO) is $13 \mathrm{~mm}$.

Symptom related factors obtained by questionnaire, the scores pre- and posttreatment maximal interincisal opening (MIO) and visual analogue scale (VAS) for pain are to be documentated and compared. Joint pain is assessed with $100 \mathrm{~mm}$ visual analogue scale with end points marked "no pain" and "worst pain ever experienced". The absence of pain is scored as 0 . If pain is present the patient is asked to select marked field from $1 \mathrm{~mm}$ to 100 $\mathrm{mm}$.

It is known that inflammation often is accompanied by pain. Evaluation and estimation of the impact of pain is a complicated matter, since pain has many different ways to interfere with everyday life. The impact of pain on the health status and quality of life in patients with chronic inflammatory joint diseases has been recognized, but there is a lack of knowledge about the specific impact of TMJ pain on daily activities in patients with clinical involvement of the TMJ. A scale for measuring the activity of daily living (ADL), (List \& Helkimo, 1995) is a useful tool for assessment of the restriction of activities of patients with TMJ disorders in their everyday life (Voog et al., 2003a; Kaselo et al., 2007; Jagur et al., 2011). 


\subsection{Radiographic investigations}

Radiological changes of the TMJ are evaluated by orthopantomography (OPTG), computed tomography (CT), magnet resonance imaging (MRI) (Ohnuki et al. 2003; Voog et al., 2003b, 2004; Whyte et al., 2006) as well as ultrasonography (C.A. Landes et al., 2007).

OPTG is mainly used to demonstrate the structural bone changes in the TMJ and it has the advantage of being easily available but gaves limited information about the above mentioned joint being an alternative method to other radiological methods. To obtain a more detailed anatomic picture, CT or MRI are recommended. By evaluating the OPTGs the following radiographic signs of bone structural changes can be achieved such as presence of erosions, flattening and osteophytes of the condyle as well as temporal bone (Rohlin et al., 1986). Erosion in condyles in the radiographs is scored according to Helenius et al. (2004) as follows: score 1 - very slight erosion; score 2 - erosion on top of the condyle; score 3 - half of condyle is eroded; score 4 - condyle totally eroded. The first report of TMJ CT was published by Suarez et al. (1980) and this method is superior to plain transcranial or transmaxillary imaging for detecting bone changes. CT allows detailed three-dimensional examination of the TMJ and it is capable to detect even small bone changes not demonstrable by conventional tomographic procedures (Raustia et al., 1985; Larheim \& Kolbensvedt, 1990). The CT sections are evaluated for presence of radiographic signs of bone changes within three regions (lateral, central and medial) of the mandibular and temporal part (eminence) of the TMJ. The recording of the signs is made in the axial, coronal and sagittal views (Emshoff et al., 2003; Voog et al., 2003). The changes are defined as follows: erosion - a local area with decreased density of the cortical joint surface including or not including adjacent subcortical bone (Fig.4), sclerosis - a local area with increased density of the cortical bony joint surface that may extend into the subcortical bone (Fig. 5), subchondral pseudocyst - a well defined, local area of bone rarefication underneath an intact cortical outlining of the joint surface, flattening - a flat bony contour deviating from the convex form (Fig. 6), osteophyte - a marginal bony outgrowth (Fig. 6). The grade of the total changes of the TMJ can be evaluated according to the scoring system developed by Rohlin \& Petersson (1989) as well.

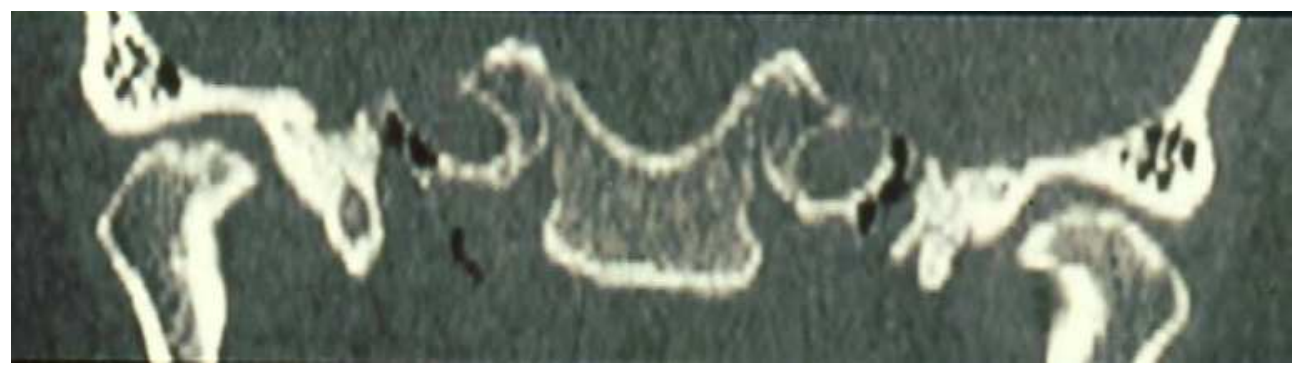

Fig. 4. Osteoarthritis of the TMJ. Signs of erosions on the surfaces of the condyles in a coronal view of the CT. An irregular outline is revealed on the condyles. The bone structure of the both glenoid fossa is normal. 


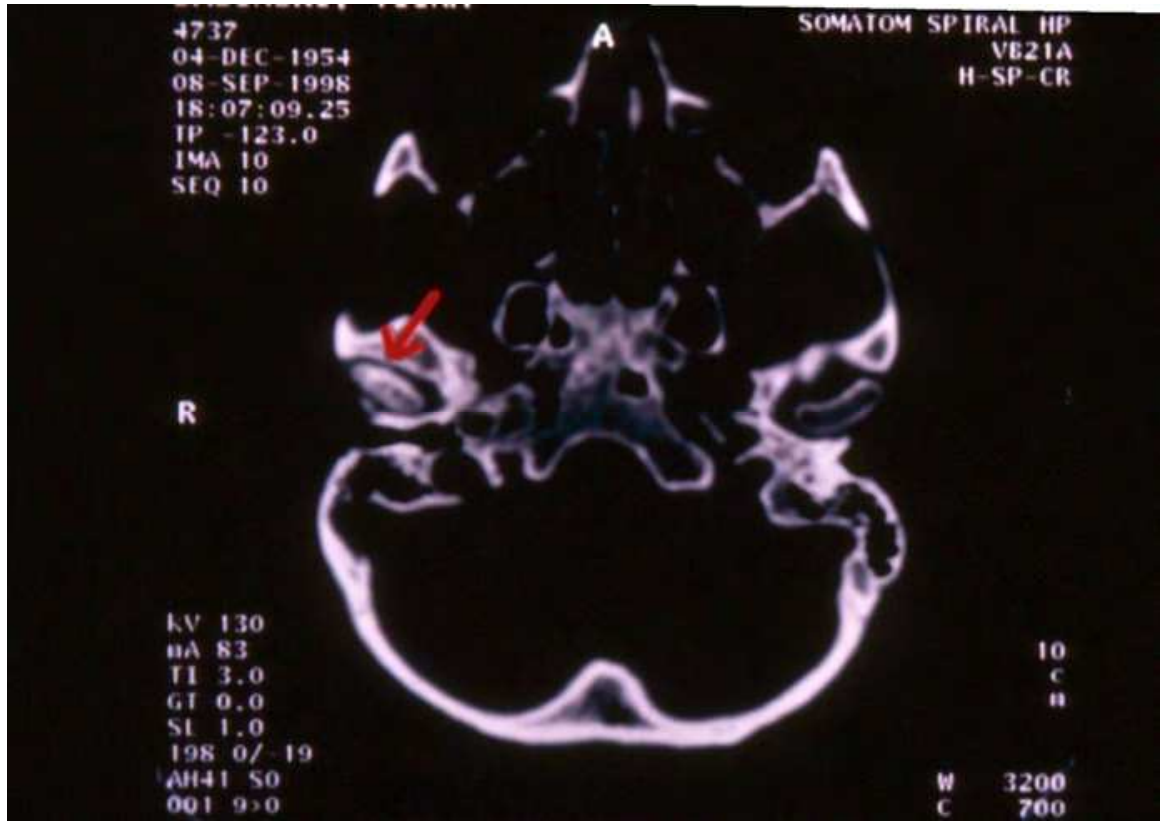

Fig. 5. Axial view of the CT. Sign of sclerosis in the medial and central parts of the right condyle of the mandible ( arrow). Reduced space is seen.

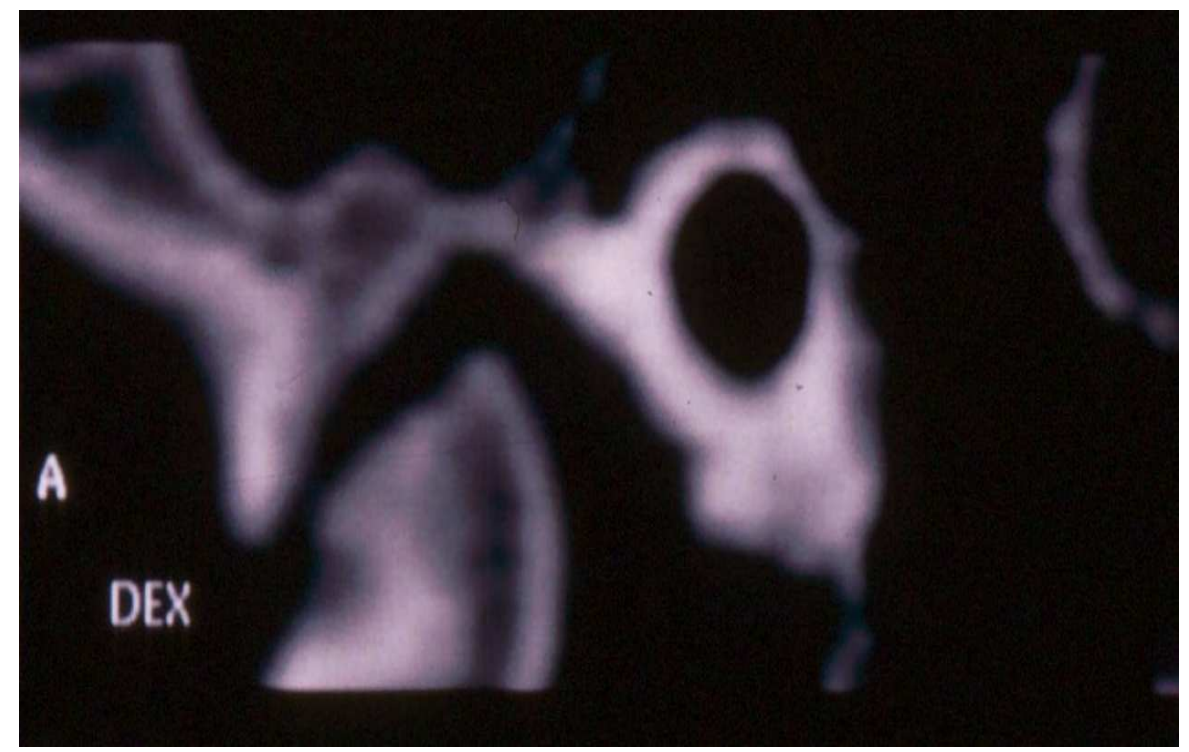

Fig. 6. Sagittal view of the CT from the left temporomandibular joint. Sign of flattening of the condyle. 
MRI has a diagnostic value for internal derangements of the TMJ and rapidly surpassing CT as the imaging method of choice. MRI can detect not only TMJ soft tissue abnormalities like disc displacements, pathology of synovial membrane or capsule, pathology in the posterior attachement but also hard tissue morphologic changes can be demonstrated with MRI (Lieberman et al., 1996; Larheim et al., 1999). Sections in the oblique sagittal plane (i.e. perpendicular to the horizontal long axis of the mandibular condyle) and oblique coronal plane (i.e. parallel with the long axis of the condyle), and bilateral temporomandibular base surface coils are used (Larheim et al., 2001) for obtaining the images (Fig. 8).

The biting device (MEDRAD; Pittsburg) which enables dynamic imaging can be used as bite blocks during the open jaw phase of the imaging procedure (Gaggl et al.,1999). Dynamic magnetic resonance imaging is a recent method that investigate directly in vivo articular function and shows much promise as a noninvasive method of the disc function, however this limitation should diminish with continuing technological advances in the imaging field. Ultrasonography has been a helpful diagnostic approach for patients with TMJ disorders, having a possibility to diagnose with considerable reliability when compared with MRI and being a sensitive tool for assessing joint function (C. Landes et al., 2000; C.A. Landes et al., 2006).

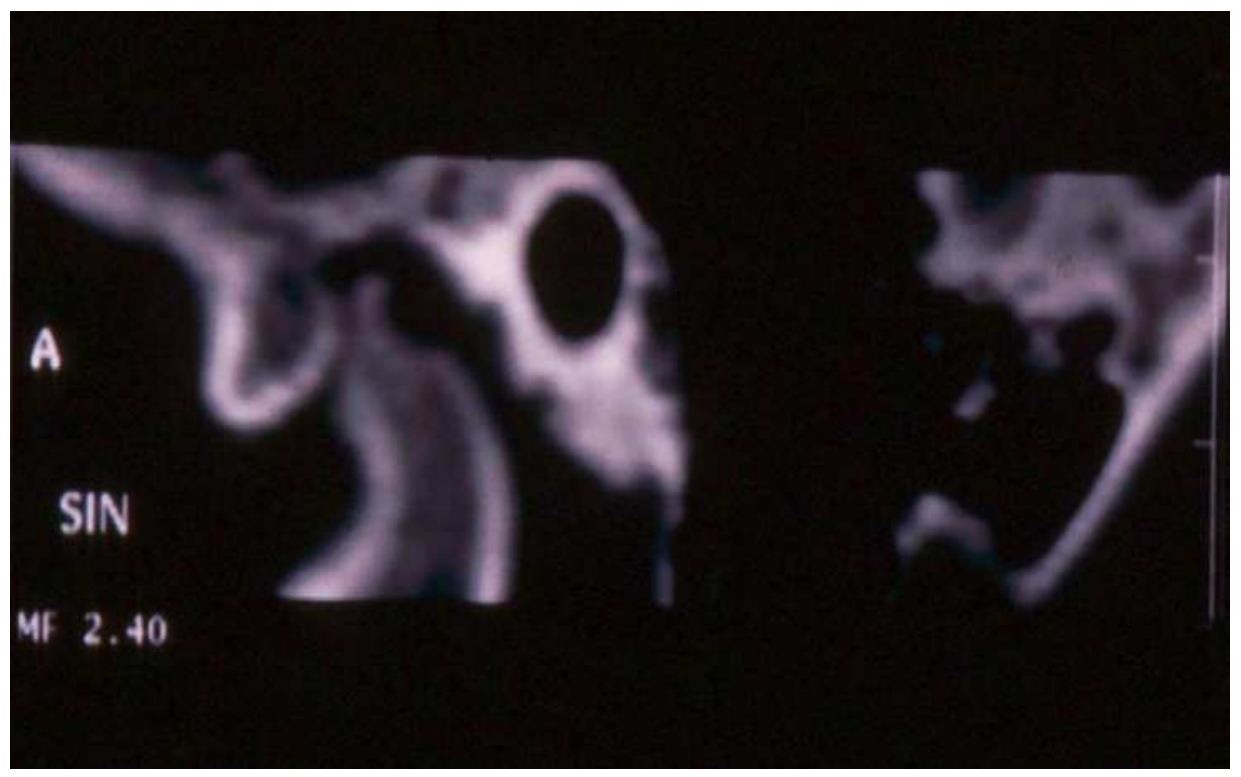

Fig. 7. An osteophyte in the medial part of the right mandibular condyle in a sagittal view of the CT., cortical destruction of the glenoid fossa surface. 


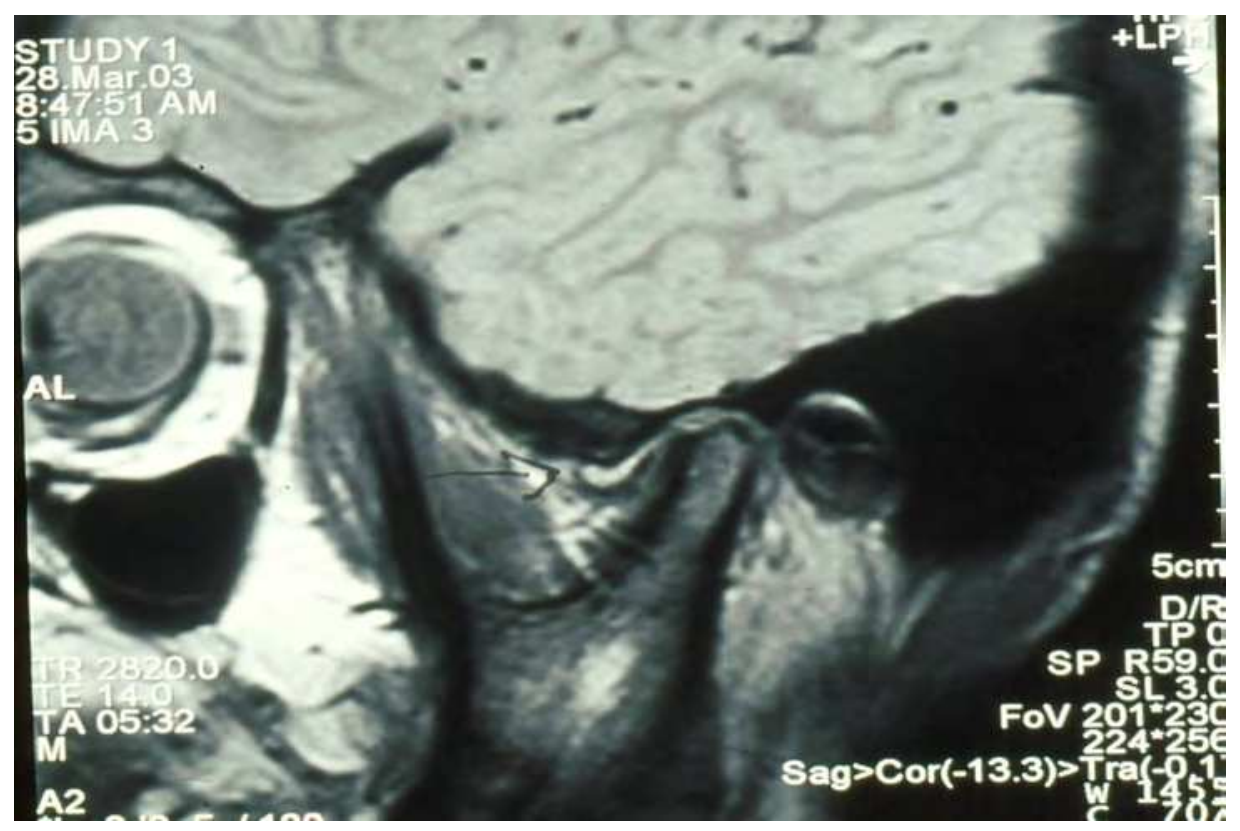

Fig. 8. Sagittal view of the MRI in a patient with internal derangement of the left TMJ. Anterior disc displacement (arrow), destruction of the disc. Changes of bone structures, effusion in the anterior recess.

\section{Temporomandibular joint arthroscopy}

\subsection{Indications for arthroscopy}

Indications for arthroscopy are radiological bone changes in TMJ characteristic to osteoarthritis with disc displacement or deformity and non effectiveness of conservative treatment with NSAIDs, intraoral splints or arthrocentesis. In practice, the decision to operate and the choice of the method seems to be a matter of the individual surgeon's training, experience, and attitude toward the surgical management of TMJ disorders. Involvement of the TMJ in patients with rheumatoid arthritis or other connective tissue diseases is rather common and arthroscopy with simultaneous biopsy is indicated in these situations. Posttraumatic complaints may also be an indication for arthroscopy. Arthroscopy is contraindicated in case of acute arthritis. In these situations as large medial osteophyts on the condyle, large central cartilaginous perforations, fibrous, fibro-osseous, osseous ankylosis are better to handle via open reduction. Arthocentesis is considered as an intervening treatment modality between nonsurgical treatment and arthroscopic surgery. All cases for arthroscopy are usually classified as advanced Wilkes (1989) stages IV and V, in rare cases stage III (Table 1).

\subsection{Technique for arthroscopy}

Arthroscopy is performed under nasotracheal general anaesthesia which makes possible to manipulate the mandible during the operation. First the zygomatic arch and the condyle are palpated. The condyle is then forced in anterior position by the assistant and the 
preauricular concavity is formed in the skin, marking a point for the injection. Usually arthroscope KARL STORZ GmbH \& Co.KG is used. Although various arthroscopic approaches to the TMJ have been described, the one most commonly used is the posterolateral approach to the upper joint space. After the condylar head of the TMJ has been determined, a marking line and puncture points are made on the skin surface (Fig. 9).

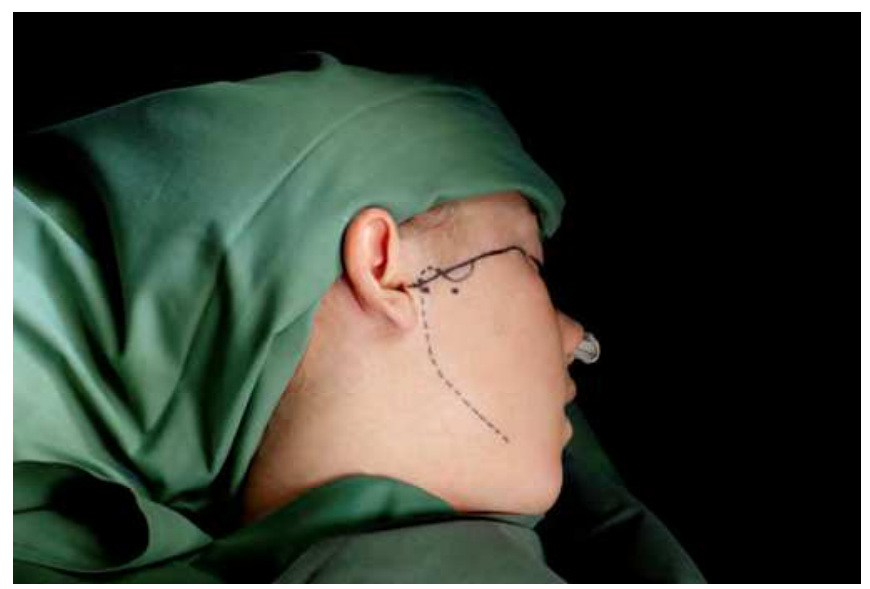

Fig. 9. A marking line and the puncture points on the skin surface for TMJ arthroscopy

The puncture site is located by manipulating the mandible anterio-inferiorly. For distension of the superior compartement and in order to avoid iatrogenic damage to the cartilaginous surfaces during introduction of the trocar, $1 \%$ lidocain solution $2,0 \mathrm{~mL}$ is inserted. The needle is aimed in a medial and slightly anteriosuperior direction until the contact with the glenoid fossa is achieved. The posterior recess of the superior joint space is reached when there is a backflow into the syringe of the solution injected into the joint space (Fig.10).

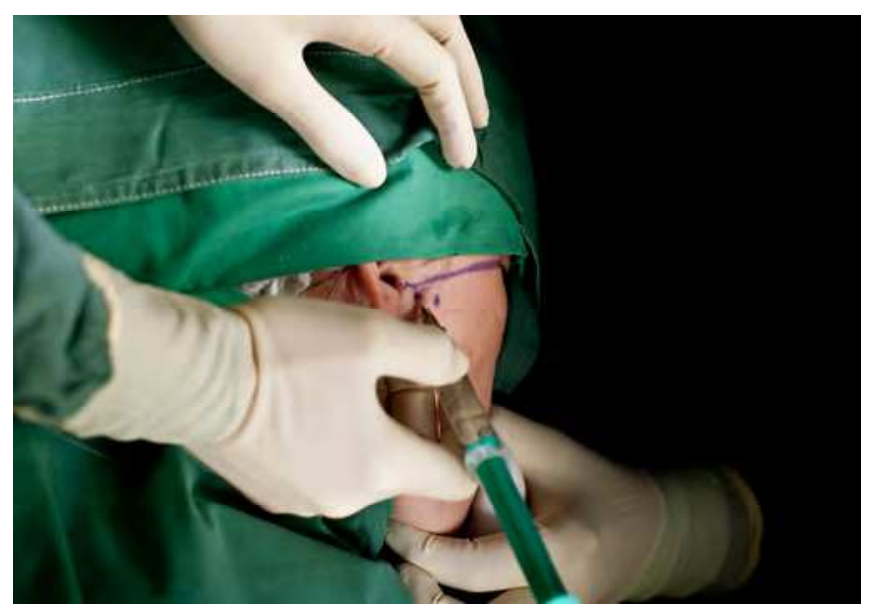

Fig. 10. Distension of the superior compartment of the right temporomandibular joint with $2 \%$ lidocaine solution. 
Through the small skin incision 0,75 - 1,0 cm from the center of the tragus at the injection site the lateral capsule is punctured with a sharp trocar in an arthroscopic sheath inserted in the same direction as the previous injection needle. The sharp trocar is exchanged for a blunt one and the arhroscopic sheath is advanced further into the upper joint space. Puncture with arthroscope sheath (trocar) with a blunt obturator inserted into upper posterior recess is performed angling it medially upward $\sim 2,5 \mathrm{~cm}$. Another skin incision is made $\sim 0,75 \mathrm{~cm}$ from the first skin incision in anterolateral direction for outflow cannula to be inserted into the upper joint anterior recess.

Following insertion of the trocar (diameter 1,8 mm, length $4 \mathrm{~cm}$ ) into the joint space, blunt obturator is removed and forward-oblique telescope $30^{\circ}$ (HOPKINS ${ }^{\circ}$ ), diameter 1,9 mm, length $6,5 \mathrm{~cm}$, fiber optic light transmission incorporated is inserted (Fig. 11).

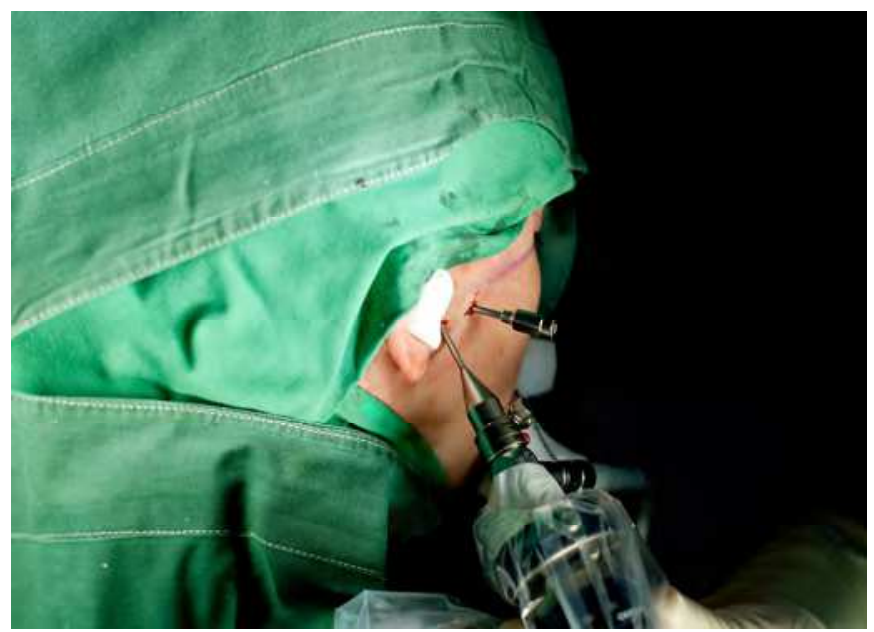

Fig. 11. Forward - oblique telescope $30^{\circ}$ (HOPKINS®) fiber optic light transmission incorporated and outflow cannula are inserted into the right upper temporomandibular joint space.

Initial recognition of anatomical structures as the superior surface of the disc, articular fossa, and internal aspects of the posterior and medial capsule is performed. The fluid level in the arthroscope sheath should move with the jaw, confirming that the sheath is correctly positioned in the joint upper space.The upper joint compartment is examined from the posterior pouch via the intermediate zone to the anterior pouch. Disc may give the impression of being obstructed against the arthrotic surface of the temporal cartilage. The anterior part of the disc surface looks usually smooth and collagen fibres could clearly seen. The condylar cartilage is normally smooth, but in case of pathology e.g. in osteoarthritis where irregularities of the surface as erosions, osteophyts can be seen. Sever arthrotic changes of both fossa cartilage and disc may also observed. Adhesions between the disc and glenoid fossa are quite common. In rare cases the arthrotic or inflammatory changes are found in the anterior recess. Upper compartment is swept clear under constant irrigation with isotonic saline solution. This manipulation allow translation of the disc along the eminence, allowing the condyle to complete its natural path. After the diagnostic 
arthroscopy has been completed, either forceps, palpation hook or blunt probe are used to cut fibres, mainly fibers of the pterygoid muscle anterior to the disc, in order to reduce pull in the anterior direction and facilitate repositioning of the disc. Cutting of adhesions facilitate repositioning of the disc. During arthroscopy a sweeping procedure between the disc and fossa release the adhesions and fibrillations increasing the mobility in the joint. Release of the adhesions and fibrillations of the superior suface of the disc and shaving the surface of articular fossa in the upper joint compartment are performed with the aid of a blunt obturator or hook and with grasping forceps, scissors or double-edged knife. Removal of the superficial layer of cortical bone induces capillar bleeding stimulating formation of fibrocartilage on bone. Quite often a displaced disc may be found during arthroscopy. Surgical procedure is completed by irrigating the joint space to remove small tissue fragments. The outflowing fluid is collected and may be retained for diagnostic purposes. Arthroscopic lysis and lavage includs also a lateral release of the upper joint compartment performed with the aid of the blunt obturator or hook.Thus the locked disc could be mobilized sufficiently. Clinical, radiographic and arthroscopic findings in patients who underwent arthroscopy are given in Table 2 (Leibur et al. 2010).

\begin{tabular}{|c|c|c|c|c|c|c|c|c|}
\hline $\begin{array}{l}\text { Signs and } \\
\text { symptoms }\end{array}$ & Sum & $\begin{array}{l}\% \\
\text { abn }\end{array}$ & Radiographic findings & Sum & $\begin{array}{l}\% \\
\text { abn }\end{array}$ & $\begin{array}{l}\text { Arthro- } \\
\text { scopic } \\
\text { findings }\end{array}$ & Sum & $\begin{array}{l}\% \\
\text { abn }\end{array}$ \\
\hline Pain & 25 & 86 & Flattening & 10 & 34 & Adhesions & 29 & 100 \\
\hline $\begin{array}{l}\text { Hypomo- } \\
\text { bility }\end{array}$ & 23 & 79 & $\begin{array}{l}\text { Bone cyst / Subchondral } \\
\text { pseudocycts }\end{array}$ & 9 & 31 & $\begin{array}{l}\text { Chondro- } \\
\text { matosis }\end{array}$ & 5 & 17 \\
\hline Closed lock & 5 & 17 & Erosions & 20 & 69 & Fibrillations & 22 & 76 \\
\hline $\begin{array}{l}\text { Intermittent } \\
\text { lock }\end{array}$ & 5 & 17 & Reduced space & 10 & 34 & Synovitis & 9 & 31 \\
\hline \multirow[t]{2}{*}{ Deviation } & 4 & 14 & Sclerosis & 8 & 27 & $\begin{array}{l}\text { Eburneation } \\
\text { of fossa }\end{array}$ & 15 & 52 \\
\hline & & & $\begin{array}{l}\text { Hypomobilityof } \\
\text { condyle Osteophyts }\end{array}$ & 45 & $\begin{array}{l}14 \\
17\end{array}$ & $\begin{array}{l}\text { Displaced } \\
\text { disc }\end{array}$ & 23 & 23 \\
\hline
\end{tabular}

Sum $=$ total number of patients with findings; $\%$ abn = percentage of individuals with abnormal findings.

Table 2. Clinical, radiographic and arthroscopic findings in patients who underwent arthroscopy $(\mathrm{N}=29)$.

Arthroscopic findings are as follows: irregularities of joint surfaces, foldings and synovitis hyperaemia of the inner wall, localising also in the posterior part of the disc, intra-articular fibrous adhesions, intracapsular adhesions, fibrillations of superior surface of the disc and arthrotic lesions of temporal cartilage, pseudowalls, foreign bodies - chondromatosis (Fig. $12,13,14,15)$. 


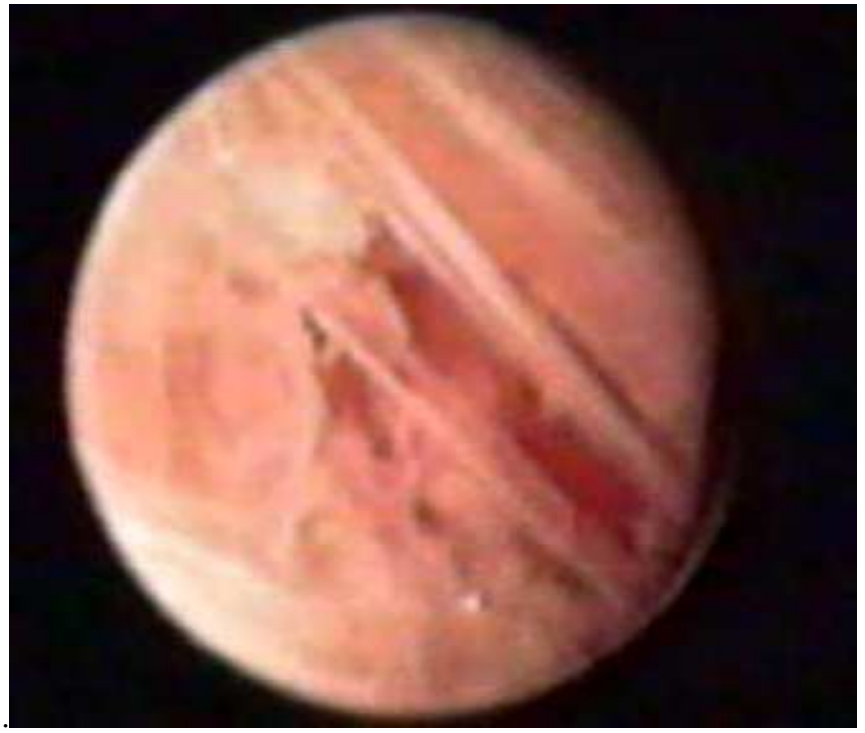

Fig. 12. Posterior recess of the superior compartment of the right TMJ. Fibrillations and pronounced adhesions with appearance irregularities of condylar surface, hyperaemia in the posterior capsular wall.

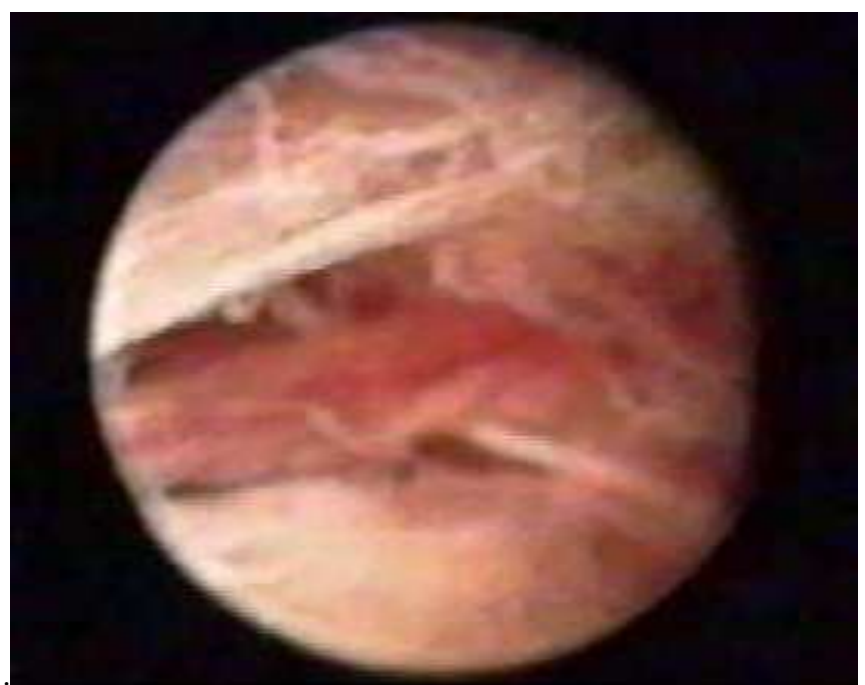

Fig. 13. Posterior recess of the superior compartment of the left TMJ. Eburneation of glenoid fossa, adhesions and fibrillations with "crab meat" appearance, mild granulations, irregularities of condylar surface, hyperaemia of the posterior attachment can be determined. 


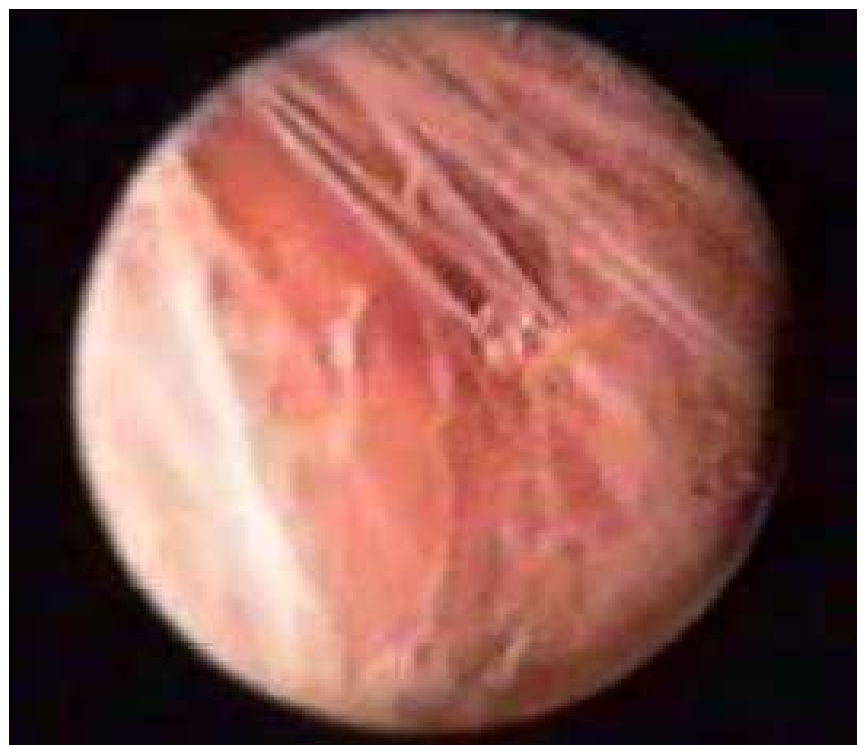

Fig. 14. Posterior recess of the superior compartment of the right TMJ. Fibrous adhesions, fibrillations and smooth fibres seen clearly. Synovial inflammation is obvious, localizing in the posterior part of the disc.

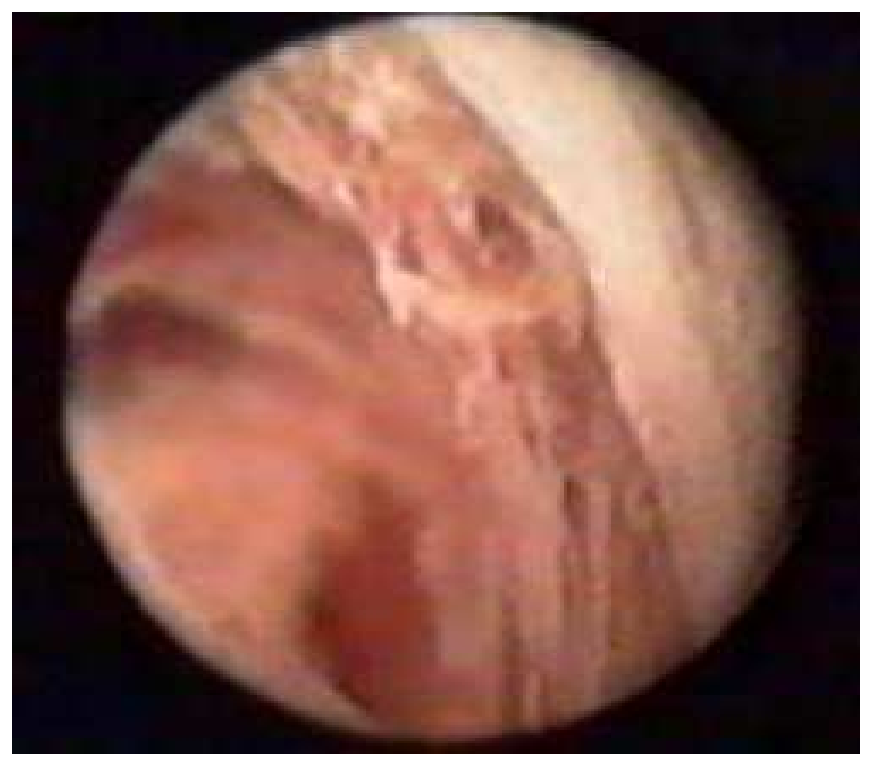

Fig. 15. Posterior recess of the superior compartment of the left TMJ. Debris on the posterior glenoid fossa wall can be seen. Fibrillations, adhesions and increased vascularization in the posterior capsular wall. 
The patients are to be followed up after 6 months and approximayely 5 years after the operation. Intravenous antibiotics at the beginning of the procedure is recommended. Concepts of irrigation are to maintain the capsule distended through the procedure. Continuous irrigation constantly cleanses a joint debris and blood, increases mobility, reliefing symptoms. It is also important to use of adjunctive therapy postoperatively to obtain maximum success with arthroscopic surgery e.g. physical therapy especially in case of haemorrage, as it may prolong healing time. A pressure dressing during the first couple of hours after the operation is recommended.

\subsection{Summary of arthroscopic findings}

A number of arthroscopic findings as fibrous adherences mainly between the disc and fossa, fibrillations with "crab meat" appearance, mild granulations, irregularities of condylar surface, foreign bodies, increased vascularisation are to be found. Synovitis in the upper joint space of the TMJ has been observed during arthroscopy and this inflamed synovium may cause pain. The alterations in the constituents of the synovial fluid affect lubrication of the joint causing stickness and decreased mobility. Synovial chondromatosis has been found in the joint space (Mercuri, 2008; Leibur et al. 2010; González-Pérez et al., 2011). Synovial chondromatosis of the TMJ in both the superior and inferior joint compartments have found due to osteoarthritis during long period $\sim 10$ years (Sato et al., 2002).

\subsection{Possible complications}

Intra- and postoperative complications for arthroscopy are rare. Bleeding may be from branches of the temporal vein during puncture. Extravasation of irrigation fluid into surrounding tissues may be occur sometimes due to leakage of the irrigating fluid into the surrounding tissues caused by accidental perforation of the TMJ capsule. This situation is easily controled if the surgeon always check the out-flow from out-flow cannula. From postoperative complications a few cases with otologic complications and nerve damage have been reported (Appelbaum et al.,1988; McCain et al., 1992). Injurie of superficial branches of facial nerve resulting to paraesthesia in the preauricular region was observed in two cases. These symptoms disappeared during one month (Leibur et al. 2010).

\section{Analysis of clinical data and results}

It has been shown that during arthroscopy several inflammatory and pain mediators causing destructive changes, foreign bodies as grains of chondromatosis are washed out elicitating joint noises (Shibuya et al., 2002; González-Pérez et al., 2011). For the patients with episodic signs and symptoms a noninvasive conservative approach is indicated (Wilkies stages I-III). Procedures currently used for the TMJ derangements as osteoarthritis/arthrosis (Wilkies stages IV and V) are: arthrocentesis, arthroscopy, arthrotomy or TMJ replacement. From arthroscopic findings fibrillation seemed to be the most common $\sim 76 \%$ (Dimitroulis, 2002). Arthroscopic lysis and lavage has been an effective treatment for TMJ disorders refractory to nonsurgical treatments (Ohnuki et al., 2003; Sanroman, 2004; Politi et al., 2007). An evaluation following temporomandibular joint arthroscopic surgery with lysis and lavage after 2 to 10,8 years treatment showed that arthroscopic surgery of the temporomandibular joint is successful in the long term for patients in case of osteoarthritis and painful motion (Sorel \& Piecuch, 2000). Assessment of symptoms reported by the patient as well as of objective signs noted on clinical examination confirms resolution of pain on movement and increased vertical opening. A significant and 
maintained improvement in maximal interincisal opening (MIO) and visual analogue scale (VAS) is also observed over the 5 years period of time (Fig. 16, 17), (Leibur et al. 2010).

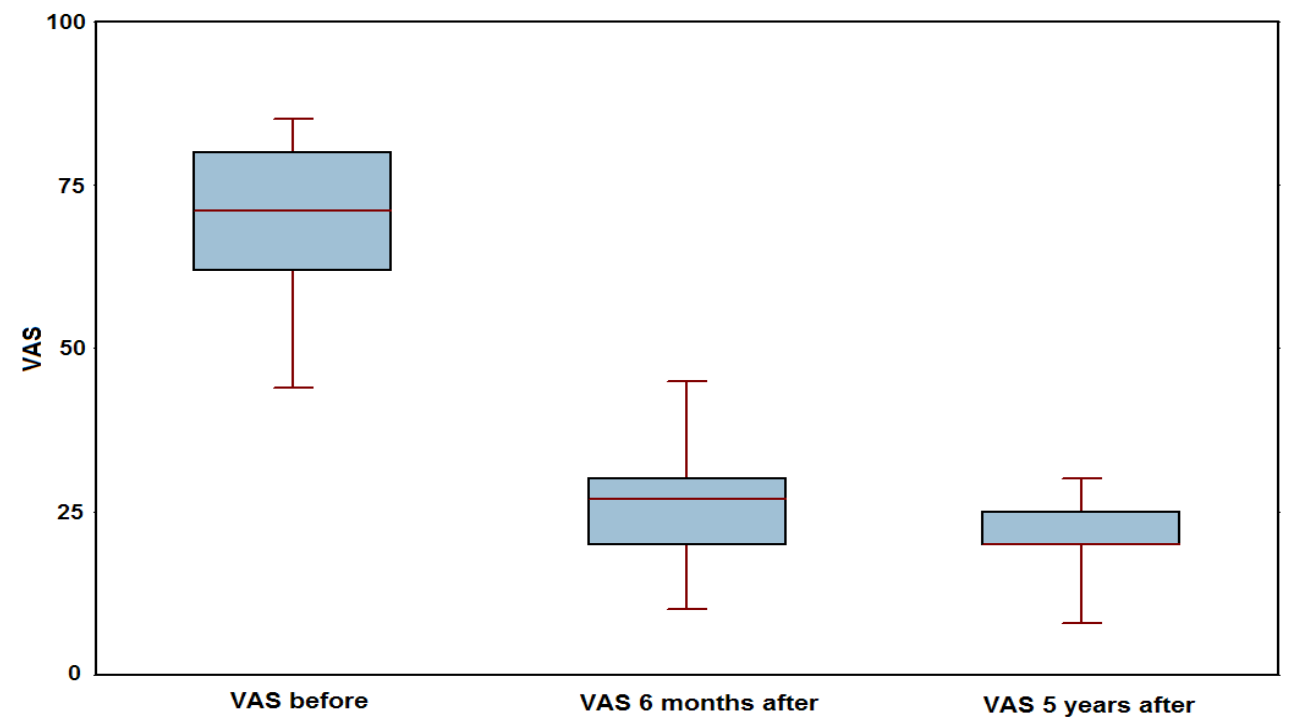

Fig. 16. Graphical representation of VAS values (median) before treatment and after 6 months and 5 years treatment in patients $(n=29)$.

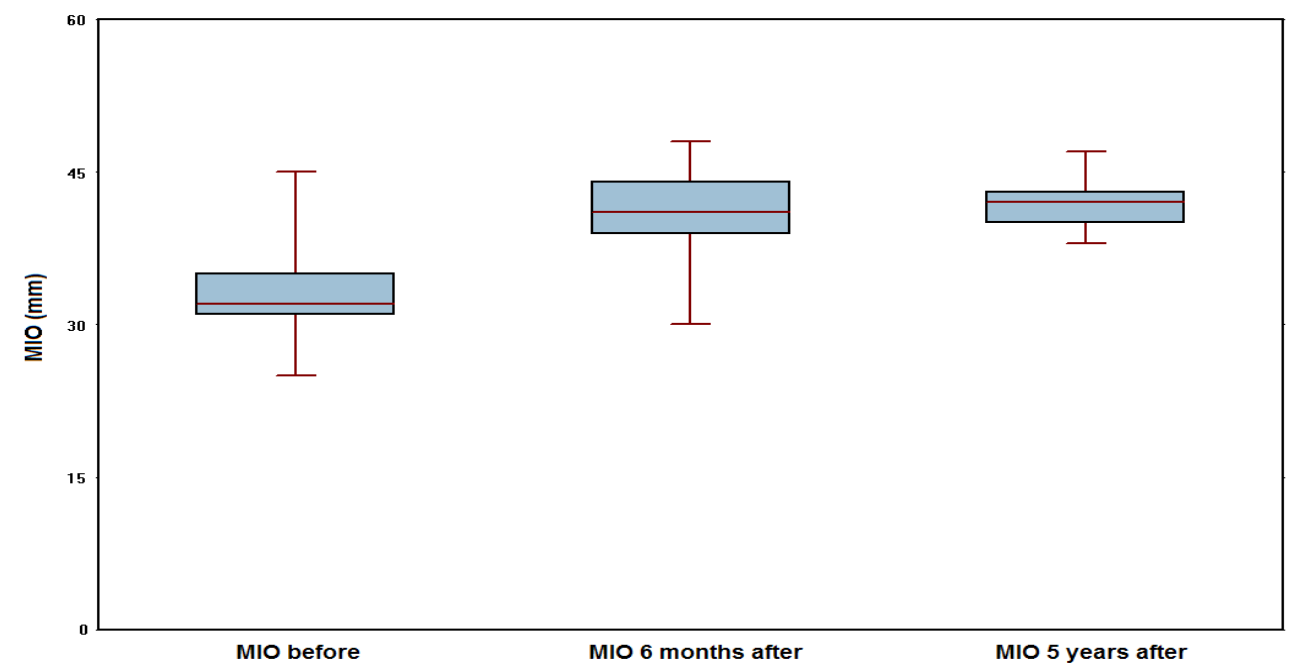

Fig. 17. Graphical representation of MIO values (median) before treatment and after 6 months and 5 years after treatment in patients $(n=29)$.

TMJ arthroscopy is especially useful when the disc has not yet been deformed. Superior joint compartment adhesions and disc immobility can be treated during arthroscopic 
procedure, leading to resolution of symptoms and return of joint function (Leibur et al. 2010). The adhesions may cause retention of the disc in its anteriorly displaced position, which may explain the failure to respond to conservative treatment.

An adherence of the disc to the fossa may be caused by an alteration of the normal lubrication of the joint as a result of intermittent joint overloading, with secondary activation of oxidative species and degradation of hyaluronic acid. Anchored Disc Phenomen could be one of the first clinical symptoms observed in the chain events that would end in a more severe internal derangement (Sorel \& Piecuch, 2000; Krug et al. 2004). Long-term results of TMJ arthroscopy have been analysed demonstrating a high accuracy for adhesions, fibrillations and degenerative changes of the bone structures. The adhesions may cause retention of the disc in its anteriorly displaced position, which may explain the failing response to conservative treatment. It has been shown that during this procedure several inflammatory and pain mediators causing destructive changes and chondromatosis are washed out elicitating joint noises (Emshoff et al., 2003; Voog et al., 2003b; Leibur et al., 2010). It is important to select the procedure with the highest probability of success and least morbidity. For the patients with episodic signs and symptoms a noninvasive, conservative approach is indicated (Wilkies stages I-III). Procedures currently used for the TMJ derangements as osteoarthritis/arthrosis (Wilkies stages IV and V) are: arthrocentesis (Sanroman, 2004), arthroscopy, arthrotomy or TMJ replacement (McCain et al.,1992; Smolka \& Iizuka, 2005). Pain and hypomobility seems to be a part of a wide spectrum of symptoms appearing in the context of chronic dysfunction of the TMJ. Some authors have reported that the major symptom has been closed lock phenomenon (Dimitroulis, 2002; Sanroman, 2004). From arthroscopic findings (Dimitroulis 2002) fibrillation seemed to be the most common $76 \%$. In other study (Leibur et al. 2010) closed lock was found in 17,2 \% and fibrillations in $75,8 \%$ of cases. Several authors (K.Murakami et al., 2000; Sorel \& Piecuch, 2000) performed long-term evaluation following temporomandibular joint arthroscopic surgery with lysis and lavage covering 10 years. On the bases of assessment of symptoms reported by the patients as well as objective signs noted on clinical examination confirmed resolution of pain on movement and increased maximal interincisial opening.. In a later study also lysis and lavage improved translation of the joint, decreased or eliminated pain. The chief presenting complaint for most patients $(86,2 \%)$ was pain preoperatively. A significant maintained decrease in VAS score was achieved after 6 months and also after 5 years follow-up. A significant and maintained improvement in MIO was also observed over the same period of time (Leibur et al., 2010). The results are comparable to those reported in the other papers (Sorel and Piecuch, 2000; Smolka and Iizuka, 2005). It is important to take into account that the sympathetic and sensory nerve fibres within the temporomandibular joint are located in the anterior recess and the retrodiscal tissue of the upper compartment. Anterior disc release may reduce the number of these nerve fibres in arthroscopic procedures, thus influencing pain dynamics. The advantages of arthroscopy compared with open joint surgery using the Jaw Pain and Function Questionnaire are that arthroscopic surgery is less invasive and associated with lower morbidity (Undt et al., 2006). No statistical differences were also observed between arthroscopic lysis and lavage and operative arthroscopy in relation to postoperative pain or MIO at any stage of the follow-up period (Gonzalez - Garcia et al., 2008). The limitation in condylar movement probably originates from changes in the upper compartement that restricts the sliding motion of the disc. Arthroscopy improved the condylar movement. Arthroscopic lysis and lavage has been found effective in $84 \%$ of patients in case of osteoarthritis of TMJ (Dimitroulis, 2005). Multiple adhesions also develop skeletal changes, with a shortened ramus. If the condition develops rapidly enough, open 
bite and rethrognathia may occur (Emshoff et al., 2003; Emshoff, 2005; Hamada et al., 2005). During arthroscopic surgery nodules of TMJ synovial chondromatosis are able to pass through the cannula by lavage with saline solution (Shibuya et al., 2002). Based on the present findings, it follows that a displaced disc, by itself, is of only limited significance. This is not surprising because the majority of individuals with derangement of the TMJ are asymptomatic (Holmlund et al., 2001; Hamada et al., 2005). The intriguing question that remains is why lavage and lysis of adhesions or high-pressure irrigation of the upper joint space should be therapeutic. The answer is, that during this procedure several inflammatory mediators available in the synovial fluid as prostaglandins (K.I. Murakami et al., 1998), cytokines (Kardel et al., 2003; Voog et al., 2003b), serotonin as pain mediator (Voog et al., 2000) etc. are washed out. In episodes of closed lock, the limitation in condylar movement probably originates from changes in the upper compartment that restrict the sliding motion of the disc. This course of events may explain the efficacy of lysis and lavage of only this joint space, as this manipulation allows translation of the disc along the eminence, allowing the condyle to complete its natural path. The data in the literature have stated that the most frequent disc displacements were anterior and anteromedial ( Sorel \& Piecuch, 2000). In episodes of closed lock, the limitation in condylar movement probably originates from changes in the upper compartment that restrict the sliding motion of the disc. The data in the literature have stated that the most frequent disc displacements were anterior and anteromedial. Using MRI pre- and postoperatively revealed that disc position remained anteriorly without reduction, disc mobility increased and deformity of the discs progressed after arthroscopic surgery (Ohnuki et al. 2003). Improvement in joint symptoms and function is not attributed so much as to the restoration of disc position as to possible release of the lateral capsular fibrosis during arthroscopy (Moses \& Lo,1992; Sorel \& Piecuch, 2000).

\section{Arthroscopy vs. arthrotomy}

There is still a group of patients whom an arthrotomy and disc surgery are necessary e.g. to treat painful clicking in patients with anteriorly displaced, nonreducing discs and limited mouth opening, irreparable disc perforation or if it is misshaped, shortened, rigid (Laskin, 2006). Large medial osteophyts on the condyle are very difficult to shave arthroscopically, and in these situations they are better to handle via arthrotomy. Large central cartilaginous perforations may need an arthrotomy and possibly discectomy, although there are data about healing of disc perforations as the bilaminar zone undergoes metaplastic changes forming pseudodisc (Moses \& Lo, 1992). The importance of disc position and shape is emphasized by many authors (Ohnuki et al., 2003; Politi et al., 2007). As a result, open joint procedures are developed to reposition the displaced disc (Holmlund et al., 2001; González - Garcia et al., 2008). Direct comparison of the clinical results are achieved in patients following arthroscopic surgery with a group of patients who underwent open surgery. The postoperative follow-up period ranged 5 to 6 years and 9 months. These results following open and arthroscopic surgery measured with the Jaw Pain and Function Questionnaire a self rating scale, originally published by Clark et al., 1989; and differentiated by Wilkes'(1989) stages. No significant difference was noted when comparing the groups 5 years postoperatively (Undt et al., 2006).

\section{Summary}

Clinical success of arthroscopy is based on several factors. Lysis and lavage remove intraarticular inflammatory and pain mediators. The release of fibrillations and adhearences 
as well as improvement in discal mobility allows to distrbute the functional stresses on the articular tissues and adverse loading on the joints is decreased. The long-term outcome of TMJ arthroscopic surgery with lysis and lavage is considered to be acceptable and effective. Fibrillations and fibrous adhesions are the most usual pathological signs of arthroscopic findings in patients with internal derangement of the TMJ. Arthroscopic releasing of these restrictive bands improves the joint mobility and contributes to reducing pain level. The results of arthroscopy offer favourable long-term stable results with regard to increasing $\mathrm{MIO}$ and reducing pain and dysfunction. The improvement in joint mobility and disc mobility will lead to adaptive changes in the hard tissues .This may implay that the arthroscopic procedure with mechanics may stop the process of further TMJ degeneration. The advantages of arthroscopy compared with open joint surgery are that arthroscopic surgery is less invasive, procedure needs less time and associated with lower morbidity.

\section{References}

Alstergren, P. \& Kopp. S. (1997). Pain and synovial fluid concentration in arthritic temporomandibular joints. Pain , Vol.72, No. 1-2 (August 1997), pp. 137-143, ISSN 0304-3959

Alstergren, P.; Kopp, S. \& Theordosson, E. (1999). Synovial fluid sampling from the temporomandibular joint: sample quality criteria and levels of interleukin- 1 beta and serotonin. Acta Odontologica Scandinavica,Vol.57, No.1 (January 2003), pp. 278282, ISSN 0001- 6357

Appelbaum, E.L.; Berg, L.F.; Kumar, A. \& Mafee, M.F. (1988). Otologic complications Following temporomandibular joint arthroscopy. Annals of Otology, Rhinology, Laryngology, Vol.97, No. 6 (November-December 1988), pp. 675-679, ISSN 0003-4894

Clark, GT.; Seligman, D.; Solberg, W.K. \& Pullinger, A.G. (1989). Guidlines for the examination and diagnosis of temporomandibular disorders. Journal of Craniomandibular Disorders, Vol.3, No.1 (Winter 1989), pp. 7-14, ISSN 0890-2739

Dimitroulis, G. (2002). A review of 56 cases of chronic closed lock treated with temporomandibular joint arthroscopy. Journal of Oral and Maxillofacial Surgery, Vol.60, No.5 (May 2002), pp. 519-524, ISSN 0278-2391

Dimitroulis, G.(2005). The prevalence of osteoarthrosis in cases of advanced internal derangement of the Tempoomandibular Joint: a clinical, surgical and histological study. International Journal of Oral \& Maxillofacial Surgery, Vol.34, No. 2 (February 2005), pp. 345-349, ISSN 0901-5027

Emshoff, R.; Brandlmaier, I.; Bertram, S.\& Rudish, A.(2003). Relative odds of temporomandibular joint pain as a function of magnetic resonance imaging findings of internal derangement, osteoarthrosis, effusion, and bone marrow edema. Oral Surgery Oral Medicine Oral Pathology Oral Radiology Endodontics, Vol. 95, No.4 (April 2004), pp. 437-445, ISSN 0904-2512

Emshoff, R.(2005). Clinical factors affecting the outcome of arthrocentesis and hydraulic distension of the temporomandibular joint. Oral Surgery Oral Medicine Oral Pathology Oral Radiology Endodontics, Vol.100, No.4 (October 2005), pp.409-414, ISSN 0904-2512

Gaggl, A.; Schults, G.; Santler, G.; Kärcher, H. \& Simbrunner, J. (1999). Clinical and magnetic resonance findings in the temporomandibular joints of patients before and after orthognathic surgery. The British Journal of Oral \& Maxillofacial Surgery, Vol. 37, No.1 (February 1999), pp. 41-45, ISSN 0266-4356 
González-Garcia, R.; Rodriguez-Campo, FJ.; Monje, F.; Sastre-Perez, J.\& Gil-Diez Usandizaga JL. (2008). Operative versus simple arthroscopic surgery for chronic closed lock of the temporomandibular joint: a clinical study of 344 arthroscopic procedures. International Journal of Oral EMaxillofacial Surgery, Vol.17, No.9 (September 2008), pp. 790-796, ISSN 0901-5027

González-Pérez, L.M., Concregado-Córdoba, J.\& Salinas-Martin, M.V. (2011). Temporomandibular joint synovial chondromatosis with a traumatic etiology. International Journal of Oral \& Maxillofacial Surgery, Vol.40, No.3 (March 2011), pp. 330-334, ISSN 0901-5027

Hamada, Y.; Kondoh, T.; Holmlund, A.B.; Iino, M.; Kobayashi, K.\& Seto, K. (2005). Influence of arthroscopically observed fibrous adhesions before and after joint irrigation on clinical outcome in patients with chronic closed lock of the temporomandibular joint. International Journal of Oral \& Maxillofacial Surgery, Vol.34, No.7 (October 2005), pp. 727-732., ISSN 0901-5027

Helenius, L.; Hallikainen, D.; Meurman, J.; Koskimies, S.; Tervahartiala, P.; Kivisaari, L.; Hietanen, J.; Suuronen, R.; Lindqvist, C. \& Leirisalo-Repo, M. (2004). HLA-DRB1* alleles and temporomandibular joint erosion in patientes with rheumatic disease. Scandinavian Journal of Rheumatology ,Vol 33, No.1 (January 2004), pp. 24-29, ISSN:0300-9742

Holmlund, A.B.\& Axelsson S. (1996). Temporomandibular arthropathy: correlation between clinical signs and symptoms and arthroscopic findings. International Journal of Oral E Maxillofacial Surgery, Vol.25, No.3, (June 1996), pp. 266-271, ISSN 0901 - 5027

Holmlund, A.B.; Axelsson, S.\& Gynther, G.W. (2001).A comparison of discectomy and arthroscopic lysis and lavage for the treatment of chronic closed lock of the temporomandibular joint: a randomized outcome study. Journal of Oral and Maxillofacial Surgery, Vol.59, No.9 (September 2001), pp. 972-977, ISSN 0278-2391

Jagur, O.; Kull, M.; Leibur, E.; Kallikorm, R.; Loorits, D.; Lember, M.\& Voog-Oras, Ü. (in print 2011). The impact of pain in TMJ on activities of daily living and bone status. Stomatologija. Baltic Dental and Maxillofacial Journal, (in print, 2011), ISSN 1392-8589

Kamada, A.; Kakudo, K.; Arika, T.; Okazaki, J.; Kano, M.\& Sakaki, T.(2000). Assay of synovial MMP-3 in temporomandibular joint diseases. Journal of Cranio-MaxilloFacial Surgery, Vol.28, No.3 (June 2000), pp.247-248, ISSN 1010-5182

Kardel, R.; Ulfgren, A.K.; Reinholt, F.P.\& Holmlund, A.B. (2003). Inflammatory cell and cytokine patterns in patients with painful clicking and osteoarthritis in the temporomandibular joint. International Journal of Oral $\mathcal{E}$ Maxillofacial Surgery, Vol. 32, No.5 (May 2003), pp. 390-396, ISSN 0901-5027

Kaselo, E.; Jagomägi, T.\& Voog, U. (2007). Malocclusion and the need for orthodontic treatment in patients with temporomandibular dysfunction. Stomatologija. Baltic Dental and Maxillofacial Journal, Vol.9, No.3, ( Autum 2007), pp.79-85, ISSN 13928589

Kim, S.J.; Park, Y.H.; Hong, S.P.; Cho, B.O.; Park, J.W.\& Kim, S.G. (2003). The presence of Bacteria in the synovial fluid of the temporomandibular joint and clinical significance: preliminary study. Journal of Oral and Maxillofacial Surgery, Vol.61, No.10 (October 2003), pp. 1156-1161, ISSN 0278-2391

Krug, J.; Jirousek, Z.; Suchmova, H.\& Germakova, E. (2004). Influence of discoplasty and discectomy of the temporomandibular joint on elimination of pain and restricted mouth opening. Acta Medica (Hradec Kralove), Vol.47, No.1 (January 2004), pp. 4753, ISSN 1211-4286 
Landes, C.; Walendzik, H. \& Klein, C. ( 2000). Sonography of the temporomandibular joint from 60 examinations and comparison with MRI and axiography. Journal of CranioMaxillo-Facial Surgery, Vol.28, No.6 (December 2000), pp.352-361, ISSN 1010-5182

Landes, C.A.; Goral, W.A.; Sader, R.\& Mack, M.G. (2007). 3-D sonography for diagnosis of disc dislocation of the temporomandibular joint compared with MRI. Ultrasound Medical Biology, Vol.32, No.5 (May 2007), pp. 633-639, ISSN 0301-5629

Larheim, T.A. \& Kolbenstvedt, A. (1990). Osseous temporomandibular joint abnormalities in rheumatic disease. Computed tomography versus hypocycloidal tomography. Acta Radiologica, Vol 31, No.4 (July 1990), pp.383-387, ISSN 0284-1851.

Larheim, T.A.; Westesson, P.- L.; Hicks, D.G.; Eriksson, L. \& Brown, D.A. (1999). Osteonecrosis of the temporomandibular joint: correlation of magnetic resonance imaging and histology. Journal of Oral and Maxillofacial Surgery, Vol.57, No.8 (August 1999), pp. 888-898, ISSN 0901-5027.

Larheim, T.A.; Westesson, P. \& Sano, T. (2001). Temporomandibular Joint Disk Displacement: Comparison in Asymptomatic Volunteers and Patients. Radiology, Vol.218, No.2 (February 2001), pp. 428-32, ISSN 0033-8419.

Laskin, D.M. (2006).Surgical Management of Internal Derangements, In: Temporomandibular Disorders. An Evidence-Based Approach to Diagnosis and Treatment, D.M. Laskin; C.S. Green; W.L. Hylander (Ed.), 469-481, Quintessence Publishing Co. Inc, ISBN 086715-447-0

Leibur, E.; Jagur, O.; Müürsepp, P.; Veede, L. \& Voog-Oras, Ü. (2010). Long-term evaluation of arthroscopic surgery with lysis and lavage of temporomandibular disorders. Journal of Cranio-Maxillo-Facial Surgery, Vol.38, No.8 (December 2010), pp.615-620, ISSN 1010-5182

Lieberman, J.M.; Gardner, C.L.; Motta, A.O. \& Schwartz, R.D. (1996). Prevalence of bone marrow signal abnormalities observed in the temporomandibular joint using magnetic resonance imaging. Journal of Oral and Maxillofacial Surgery , Vol.54, No. 4 (April 1996), pp. 434-439, ISSN 0901-5027..

List, T. \& Helkimo, M. (1995). A scale for measuring the activities of daily living (ADL) of patients with craniomandibular disorders. Swedish Dental Journal, Vol.19, No.1 (January 1995), pp. 33-40, ISSN 0001-6357.

McCain, J.P.; Sanders, B.; Koslin, M.G.; Quinn, J.H.; Peters, P.B. \& Indresano, A.T. (1992). Temporomandibular joint arthroscopy : a 6-year multicenter retrospective study of 4,831 joints. Journal of Oral and Maxillofacial Surgery, Vol.50, No.9 (September 2002), pp.926-930, ISSN 0278-2391

Mercuri, L.G. (2008). Synovial chondromatosis of the temporomandibular joint with medial cranial fossa extension. International Journal of Oral \& Maxillofacial Surgery, Vol.37, No.7 (July 2008), pp. 684-685, ISSN 0901 - 5027

Moses, J.J. \& Lo, H. (1992). The treatment of internal derangement of the temporomandibular joint - an arthroscopic approach. Oral Surgery Oral Diagnosis, Vol.3 (1992), pp. 5-11, ISSN 0788-6020

Murakami, K.I.; Shibata, T.; Kubota, E.\& Maeda, H. (1998). Intra-articular levels of prostaglandin $\mathrm{E}_{2}$, hyaluronic acid, and chondroitin - 4 and - 6 sulfates in the temporomandibular joint synovial fluid of patients with internal derangement. Journal of Oral and Maxillofacial Surgery, Vol.56, No.2 ( February 1998), pp. 199-203, ISSN 0278-2391 
Murakami, K.; Segami, N.; Okamoto, I.; Takahashi, K. \& Tsuboi, Y. (2000). Outcome of arthroscopic surgery for internal derangement of the temporomandibular joint: long - term results covering 10 years. Journal of Cranio-Maxillo-Facial Surgery, Vol.28, No.3 (March 2000), pp. 264 - 271, ISSN 1010-5182

Onishi, M. (1975). Arthroscopy of the temporomandibular joint (author's transl.). Journal of Japanese Stomatological Association, No.42, (June 1975), pp. 207-213, ISSN 0300-9149

Onishi, M. (1980).Clinical application arthroscopy in the temporomandibular joint diseases. Bulletin Tokyo Medical Dental University. No. 27(1980), pp. 141-148.

Ohnuki, T.; Fukuda, M.; Iino, M. \& Takahahshi, T. (2003). Magnetic resonance evaluation of the disk before and after arthroscopic surgery for temporomandibular disorders. Oral Surgery Oral Medicine Oral Pathology Oral Radiology Endodontics, Vol.96, No.2 (February 2003), pp.141-148. ISSN 0904-2512

Paegle, D.I.; Holmlund, A.B.; öStlund, M.R. \& Grillner, L. (2004). The occurence of antibodies against Chlamydia species in patients with monoarthritis and chronic closed lock of the temporomandibular joint. Journal of Oral and Maxillofacial Surgery, Vol.62, No.4 (April 2004), pp. 435-439, ISSN 0278-2391

Politi, M.; Sembronio, S.; Robiony M.; Costa, F.; Toro, C. \& Undt, G. (2007). High condylectomy and disc repositioning compared to arthroscopic lysis, lavage and capsular strech for the treatment of chronic closed lock of the temporomandibular joint. Oral Surgery Oral Medicine Oral Pathology Oral Radiology Endodontics, Vol. 103, No.1 (January 2007), pp.27 - 33. ISSN 0904-2512

Raustia, A.M.; Pyhtinen, J.\& Virtanen, K.K. (1985). Examination of the temporomandibular joint by direct sagittal computed tomography. Clinical Radiology, Vol. 36, No. 3 (May 1985), pp. 291-296, ISSN 0009-9260.

Rohlin, M.; Akerman, S.; \& Kopp, S. (1986). Tomography as an aid to detect macroscopic changes of the temporomandibular joint. Acta Odontologica Scandinavica, Vol. 44, No.3 (June 1986), pp.131-140,ISSN 0001-6357

Rohlin, M. \& Petersson, A. (1989). Rheumatoid arthritis of the temporomandibular joint: radiologic evaluation based on standard reference films. Oral Surgery, Oral Medicine, and Oral Pathology, Vol. 67, No. 5 (May 1989), pp. 594-599, ISSN0030-4220.

Sanroman, J.F. (2004). Closed lock (MRI fixed disc): a comparison of arthrocentesis and arthroscopy. International Journal of Oral \& Maxillofacial Surgery, Vol.33, No.4 (April 2004), pp. 344-348, ISSN 0901 - 5027

Sato, J.; Segami, N.; Suzuki, T.; Yoshitake, Y.\& Nishikawa, K. (2002).The expression of fibroblast growth factor receptor 1 in chondrocytes in synovial chondromatosis of thetemporomandibular joint. Report of two cases. International Journal of Oral $\mathcal{E}$ Maxillofacial Surgery, Vol.31, No.7 (July 2002), pp. 532-536, ISSN 0901 - 5027

Schmelzle, R. (1989). Lokalanästhesie. In: Zahnärztliche Chirurgie. 2. Auflage Urban \& Schwarzenberg. München-Wien Baltimore, p.19, ISBN 3-541-15290-7

Shibuya, T.; Kino, K.; Yoshida, S. \& Amagasa, T. (2002). Arthroscopic removal of nodules of synovial chondromatosis of the temporomandibular joint. Cranio, Vol.20, No.4 (October 2002), pp. 304-306, ISSN 0886-9634

Smolka, W. \& Iizuka, T. (2005). Arthroscopic lysis and lavage in different stages of internal derangement of the temporomandibular joint: correlation of preoperative staging to arthroscopic findings and treatment outcome. Journal of Oral and Maxillofacial Surgery, Vol.63, No.4 (April 2005), pp. 471-478, ISSN 0278-2391 
Sommer, O.J.; Aigner, F.; Rudisch, A.; Gruber, H.; Fritsch, H.; Millesi, W. \& Stiskal, M. (2003). Cross-sectional and functional imaging of the temporomandibular joint: radiology, pathology, and basic biomechanics of the jaw. Radiographics.,Vol. 23, No.6 (November-December 2003), pp. e14, ISSN 0271-5333

Sorel. B. \& Piecuch, J.F. (2000). Long-term evaluation following temporomandibular joint arthroscopy with lysis and lavage. International Journal of Oral $\mathcal{E}$ Maxillofacial Surgery, Vol.29, No.4 (August 2000), pp. 532-536, ISSN 0901 - 5027

Suarez, F.R.; Bhussry, B.R.; Neff, P.A.; Huang, H.K. \& Vaughn, D. (1980). A preliminary study of computerized tomographs of the temporomandibular joint. The Compendium on continuing education in general dentistry, Vol. 1, No. 3 (May-June 1980), pp.217-222, ISSN 0196-1756.

Tag, H. (1939). Arthroscope. Journal of Japanese Orthopedic Association, No.14, pp.359 - 362.

Tallents, R.H.; Macher, D.J.; Kyrkanides, S.; Katzberg, R.W. \& Moss, M.E. (2002). Prevalence of missing posterior teeth and intraarticular temporomandibular disorders. Journal of Prosthetic Dentistry, Vol. 87, No.1 (January 2002), pp. 45-50, ISSN 0022-3913

Undt, G.; Murakami, K.I.; Rasse, M \& Ewers, R. (2006). Open versus arthroscopic surgery for internal derangement of the temporomandibular joint: A retrospective study comparing two centers results using Jaw Pain and Function Questionnaire. Journal of Cranio-Maxillo-Facial Surgery, Vol.34, No.4 (June 2006), pp.234-241, ISSN 1010-5182

Voog, Ü.; Alstergren, P., Leibur, E.; Kallikorm, R. \& Kopp, S. (2000). Immediate effect of the serotonin antagonist granisetron on temporomandibular joint pain in patients with systemic inflammatory disorders. Life Sciences, Vol.68, No.5, ( December 2000), pp. 591-602, ISSN 0024-3205

Voog, Ü.; Alstergren, P.; Leibur, E.; Kallikorm, R. \& Kopp, S. (2003a). Impact of temporomandibular joint pain on activities of daily living in patients with rheumatoid arthritis. Acta Odontologica Scandinavica,Vol.61, No.5 (October 2003), pp. 278-282, ISSN 0001- 6357

Voog, Ü.; Alstergren, P.; Eliasson, S.; Leibur, E.; Kallikorm, R. \& Kopp, S. (2003b). Inflammatory mediators and radiographic changes in temporomandibular joints in patients with rheumatoid arthritis. Acta Odontologica Scandinavica, Vol.61, No.1 (January 2003), pp. 57-64, ISSN 0001- 6357

Voog, Ü.; Alstergren, P.; Eliasson, S.; Leibur, E.; Kallikorm, R. \& Kopp, S. (2004). Progression of radiographic changes in the temporomandibular joints of patients with rheumatoid arthritis in relation to inflammatory markers and mediators in the blood. Acta Odontologica Scandinavica, Vol.62, No.1 (January 2004), pp. 7-13, ISSN 0001- 6357

Warden, S.J. \& Haney, E.M. (2008). Skeletal effects of serotonin (5-hydroxytryptamine) transporter inhibition: evidence from in vitro and animal-based studies. Journal of Musculoskeletal Neuronal Interaction,Vol.8, No.2 (February 2008), pp. 121-132, ISSN 1108-7161

Whyte, A.M.; McNamara, D.; Rosenberg, I. \& Whyte, A.W. (2006). Magnetic resonance imaging in the evaluation of temporomandibular joint disc displacement. International Journal of Oral \& Maxillofacial Surgery, Vol.35, No.8 (August2006), pp.696-703, ISSN 0901 - 5027

Wilkes, C.H. (1989).Internal derangements of the temporomandibular joint. Pathological variations. Archives of Otolaryngology, Head Neck Surgery, Vol.115, No.4 (April 1989), pp. 469-477, ISSN 0886-4470 


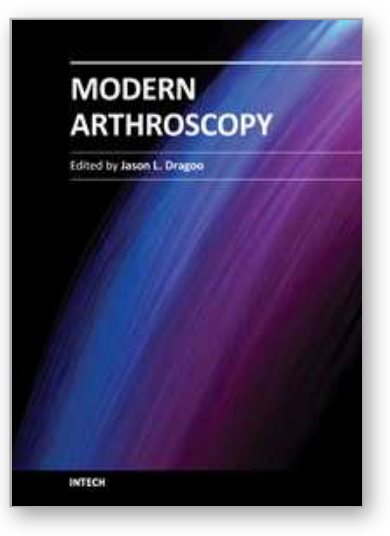

\author{
Modern Arthroscopy \\ Edited by Dr Jason L. Dragoo
}

ISBN 978-953-307-771-0

Hard cover, 302 pages

Publisher InTech

Published online 09, December, 2011

Published in print edition December, 2011

Modern Arthroscopy will assist practitioners to stay current in the rapidly changing field of arthroscopic surgery. The chapters in this book were written by a panel of international experts in the various disciplines of arthroscopy. The goals of this text are to present the classical techniques and teachings in the fields of Orthopaedics and Dentistry, but also to include new, cutting-edge applications of arthroscopy, such as temporomandibular arthroscopy and extra-articular arthroscopy of the knee, just to name a few. We hope Modern Arthroscopy becomes a core reference for your arthroscopic surgery practice.

\title{
How to reference
}

In order to correctly reference this scholarly work, feel free to copy and paste the following:

Edvitar Leibur, Oksana Jagur and Ulle Voog-Oras (2011). Temporomandibular Joint Arthroscopy, Modern Arthroscopy, Dr Jason L. Dragoo (Ed.), ISBN: 978-953-307-771-0, InTech, Available from: http://www.intechopen.com/books/modern-arthroscopy/temporomandibular-joint-arthroscopy

\section{INTECH}

open science | open minds

\author{
InTech Europe \\ University Campus STeP Ri \\ Slavka Krautzeka 83/A \\ 51000 Rijeka, Croatia \\ Phone: +385 (51) 770447 \\ Fax: +385 (51) 686166 \\ www.intechopen.com
}

\author{
InTech China \\ Unit 405, Office Block, Hotel Equatorial Shanghai \\ No.65, Yan An Road (West), Shanghai, 200040, China \\ 中国上海市延安西路65号上海国际贵都大饭店办公楼 405 单元 \\ Phone: +86-21-62489820 \\ Fax: $+86-21-62489821$
}


(C) 2011 The Author(s). Licensee IntechOpen. This is an open access article distributed under the terms of the Creative Commons Attribution 3.0 License, which permits unrestricted use, distribution, and reproduction in any medium, provided the original work is properly cited. 